\title{
NUMERICAL MODELING OF ORTHOTROPIC CONCRETE EXPANSION DUE TO ALKALI-AGGREGATE REACTION WITH A PARAMETRIC MODEL
}

\author{
R. Carrazedo ${ }^{1}$, R. A. K. Sanches ${ }^{1}$, L. A. de Lacerda $^{2}$ \\ ${ }^{1}$ Department of Civil Engineering, Technological Federal University of Paraná (rog- \\ erioc@utfpr.edu.br) \\ ${ }^{2}$ Department of Civil Structures, Institute of Technology for Development - LACTEC
}

\begin{abstract}
The alkali-aggregate reaction (AAR) in concrete structures consists in a chemical deleterious reaction between alkalis liberated during hydration of cement and reactive minerals present on aggregates. The process leads to the formation of a gel, which in presence of hydroxyl ions expands, causing cracks in concrete, promoting its volume variation, followed by reduction of important properties, such as the Young's modulus and mechanical strength. Modeling of a structure subjected to AAR expansion may predict the structural displacements and strains due to the reaction, enabling programming efficient structural maintenance operations, reducing temporary interruptions and also increasing safety conditions.

As such, this work presents a parametric model for simulating the orthotropic concrete expansion due to alkali-aggregate reaction, based on Carrazedo and Lacerda, 2008 [1].
\end{abstract}

Keywords: Concrete, Alkali Aggregate Reaction, Numerical Modeling, Parametrical Model.

\section{INTRODUCTION}

The alkali-aggregate reaction (AAR) is a chemical deleterious reaction between alkalis liberated during hydration of cement and reactive minerals present on aggregates. According to the aggregate mineralogical composition, one may classify the AAR in three different types: alkali-silica reaction (ASR), alkali-silicate reaction and alkali-carbonate reaction (ACR).

The alkali-silica reaction, object of this study and the main AAR type observed in Brazil, leads to the formation of a gel, which, in presence of hydroxyl ions, expands promoting concrete volume variation and cracks, followed by reduction of important properties such as the Young's modulus and mechanical strength.

The ASR is indeed complex and its development mechanism has not yet been completely elucidated. However the main factors which stimulate ASR growth and development are [2]:

- Content of alkalis on concrete pore fluid, liberated mainly during the cement hydration reaction; 
- Amount, size and reactivity of employed aggregates;

- Humidity, which causes the hydroxyl ions to be absorbed by the hygroscopic ASR gel, leading to expansion;

- Porosity, which confines the gel;

- Temperature, which increases the reaction rate as silica becomes prone to react with higher temperatures;

- Stress state, which tends to limit concrete free expansion.

As a consequence of this complexity, beyond its heterogeneity and random distribution inside a structure, several researchers around the world have studied the concrete expansion due to alkali-aggregate reaction, resulting in a large number of mathematical models with different approaches.

One of the first models proposed addressed the problem in a probabilistic way, by means of ionic diffusion and capillary pressure [3]. Similarly, analytic models deal with the ions diffusion through the barrier created by the reaction gel $[4,5]$.

Another approach considers the thermodynamic reaction in a microscopic way, in which the relation between reaction and expansion is given by Arrhenius law [6-8]. These models, in general, employ an association between the factors that influence the alkaliaggregate reaction in order to determine the expansion ratio. Also employing Arrhenius law, Carey et al. [9] modeled the gel concentration and diffusion in order to obtain its distribution in a structure, leading to coupled equations which are numerically solved employing the finite element method. Among those, there are other expansion models that employ the factors that affect the AAR for evaluating the expansion [10,11]. In a similar way, parametric models also employ the factors that affect the AAR as equation parameters to simulate the concrete expansion [1, 12-14].

One recent approach, presented by Comby-Peyrot et al. [15], models both aggregates and cement paste, considering in a probabilistic way the aggregate spatial distribution. Applied to the AAR, the model allows observing the Young's modulus reduction and the cracking on surface, considering the interaction between gel and cement matrix. However, the model complexity does not allow application to large structures in the present context. In a similar way, Dunant and Scrivener [16] modeled the aggregate cracking caused by gel bags randomly distributed inside the concrete, employing a damage model to get the modeling in an appropriate scale.

Another recent approach is based on the saturated porous media theory of Biot, where the model comprehends two elastic materials, the gel produced by AAR and the concrete skeleton. The problem may be studied by damage theory [17] or by fracture mechanics $[18,19]$. Some simplified numerical models may also be found on literature, using finite elements as an analogy to the thermal expansion with retro-analysis [20, 21]. Some advanced numerical models considers anisotropy [22], concrete ageing [23], and orthotropic behavior [24].

Independently to the adopted model for predicting the concrete expansion due to $\mathrm{AAR}$, the behavior characterization along time on structures with large volumes, such as 
dams and industrial plants, is of great interest in the economic point of view. This pathology may reduce significantly the structure life span, and there are several cases of structures with AAR diagnosed as potentially deleterious. The mathematical modeling of a structure which presents this pathology may forecast, with reasonable precision, the structural displacements due to the reaction, allowing programming maintenances, and so, increasing the structural safety.

This paper presents the development of a computational model for orthotropic concrete expansion under AAR effects, considering the stress state influence on the expansion. The model has been developed to be used within the commercial software Ansys ${ }^{\circledR}$ and represents one step forward Carrazedo's research [25], where a parametric model was proposed for simulating the isotropic volumetric expansion of concrete due to alkali-aggregate reaction.

\section{MODEL DESCRIPTION}

This research involves a series of modifications in the parametric model based on [1, $2,13]$, seeking to increase the fidelity level on forecasting damage due to concrete expansion as a consequence of AAR.

The parametric model employed consists in obtaining the spatial distribution for the factors that affect the alkali-aggregate reaction, normalizing them, and employ one equation which correlates these factors in order to obtain the volumetric strain ratio due to AAR. One may note that the influence on expansion ratio due to AAR is mainly due to humidity, temperature, stress and material reactivity.

Therefore, in this chapter the steps for implementing the new model are describe, as well as the modifications carried out to refine the existent model.

\subsection{Influence factors and normalization}

As previously described, the concrete expansion ratio due to alkali-aggregate reaction is strongly affected by humidity, temperature, stress state, mineral reactivity and amount of free alkaline ions. These are the factors employed here for expansion modeling.

Each factor plays a different role in the expansion process. With respect to the constituting materials and its reactivity, aggregates from different sources are usually employed in a large structure and it may occur that some of them may be reactive aggregates. This causes a non-homogeneous material type distribution, leading to the existence of points with concentration of reactive aggregates. This distribution is indeed complex, and in general is simplified to only two reactivity constants. The first material constant defines the maximum volumetric strain allowed to concrete and the second is related to the strain velocity.

Temperature modifies the velocity in which the gel is generated, affecting the velocity in which the structure expands, but has no influence on final expansion amount. Humidity is preponderant on AAR gel formation. The hydroxyl ions are absorbed by the gel, leading to expansion, and also to provide its mobility on structure. The humidity is used in this methodology to determine two fields: the humidity field and the porosity field. 
Regarding to the stress state, an initial analysis not considering the AAR strains is made. Afterwards, strains due to AAR are added, which generates internal pressures and confining stresses, and then the mechanic model is recalculated.

After determining the influence fields, they are normalized into influence factors by means of linear laws, as presented in Figure 1, which are governed by constants $k_{\mathrm{p}}, \mathrm{k}_{\mathrm{c}}, \mathrm{k}_{\mathrm{m}} \mathrm{e} \mathrm{k}_{\mathrm{t}}$. Each conversion law is determined to represent the corresponding effect of each field inside the expansion process.

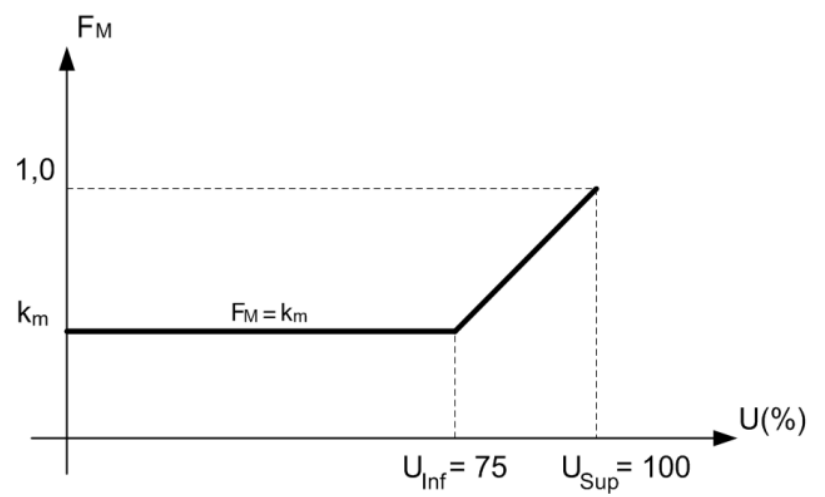

(a) - Humidity

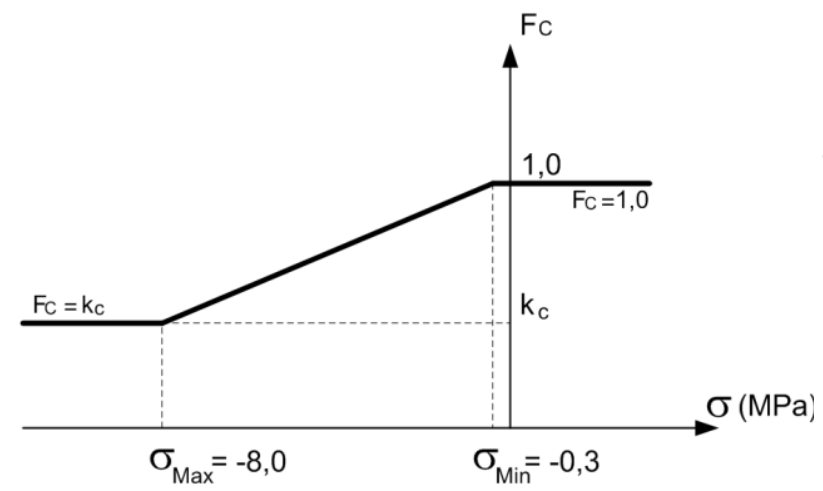

(c) - Stress State

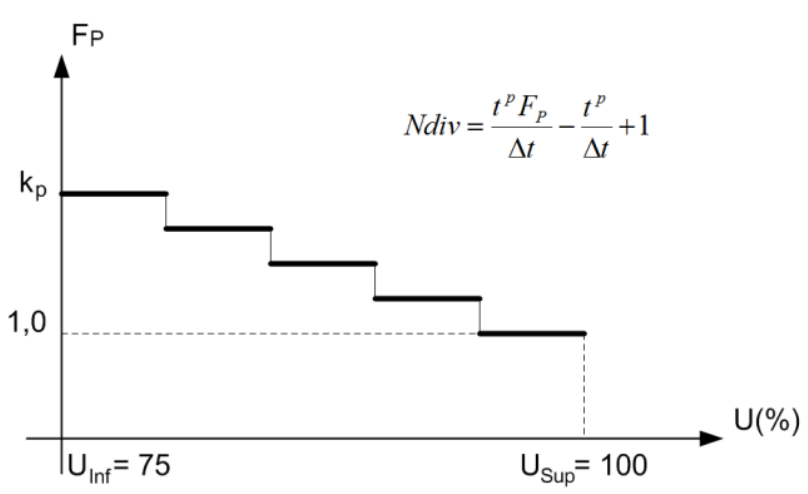

(b) - Porosity

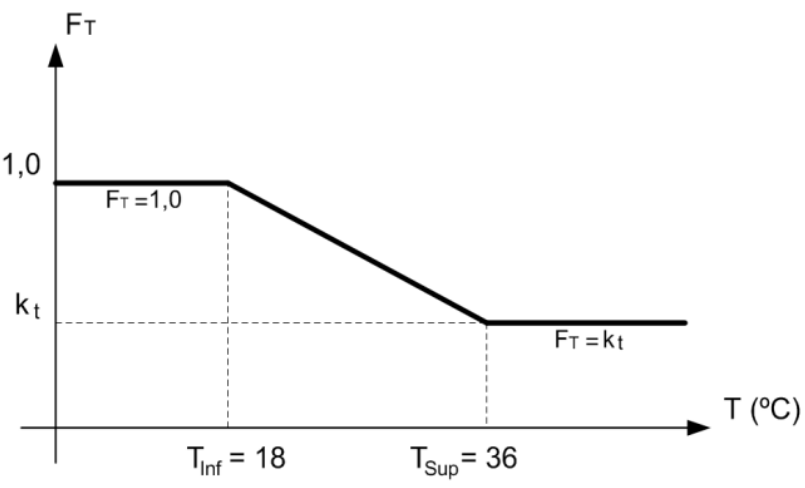

(d) - Temperature

Figure 1. Influence Factors $\left(\mathrm{F}_{\mathrm{M}}, \mathrm{F}_{\mathrm{p}}, \mathrm{F}_{\mathrm{C}}, \mathrm{F}_{\mathrm{T}}\right)$ and Calibration variables $\left(\mathrm{k}_{\mathrm{p}}, \mathrm{k}_{\mathrm{c}}, \mathrm{k}_{\mathrm{m}}, \mathrm{k}_{\mathrm{t}}\right)$. Source: (a), (c) and (d) [12], (b) [1].

Note: Ndiv is the division number of the porosity law, $\mathrm{t}^{\mathrm{p}}$ is the porous filling time and $\Delta \mathrm{t}$ is the adopted time step.

\subsection{Equation for the concrete expansion due to AAR}

Carrazedo and Lacerda proposed an exponential equation able to represent the basic characteristics of AAR expansion [1]:

$$
\varepsilon_{R A A}=\mathrm{H}\left(t-t^{p} F_{P}\right) \varepsilon_{v o l}^{\max }\left[1-e^{\frac{-\left(t-t p^{2} F_{P}\right)}{A_{1} F_{T}}}\right] \sqrt{F_{C} F_{M}}
$$

in which $H$ is the Heaviside function, $\varepsilon_{v o l}^{\max }$ is the asymptotic free volumetric strain value due to AAR, $A_{1}$ is the reactivity index, $F_{T}, F_{P}, F_{C} \mathrm{e} F_{M}$ are normalized influence factors of tempera- 
ture, porosity, stresses and humidity, respectively, and $t^{p}$ is the time (age) when the occurs the total filling of the porous by gel. This equation has its basis on the expansion equations and the expansion ratio equations presented by [11-13].

\subsection{Implementation}

This methodology has been implemented in the commercial finite element software Ansys $@$. Ansys $@$ is a commercial software for computational simulations of engineering problems which allows inclusion of user programmable routines, called "User Programmable Features" (UPF), employing Fortran` programming language.

Among the several routines where the program allows changes and manipulations, the chosen one is the USERCR, in which the laws for the influence factors normalization are programmed, as well as the function that calculates the expansion ratio due to AAR. This routine, usually employed to evaluate creep, has been used because it allows evaluating the stress state and the orthotropic expansion of the element.

\section{VALIDATION EXAMPLES}

\subsection{Accelerated test in a cubic concrete specimen}

As a first example, in order to validate the orthotropic expansion, we modeled an accelerated test in a cubic concrete specimen. Each face is submitted to a different loading, in order to observe the relative independency of each direction. At faces $\mathrm{z}=0$ and $\mathrm{z}=30 \mathrm{~cm}$, displacement in $\mathrm{z}$ direction is constrained. At face $\mathrm{y}=0$, displacement in $\mathrm{y}$ direction is constrained, and at face $\mathrm{y}=30 \mathrm{~cm}$ a pressure of $6000 \mathrm{kN} / \mathrm{m}^{2}$ is applied. At face $\mathrm{x}=0, \mathrm{x}$ displacement is also constrained and at face $\mathrm{x}=30 \mathrm{~cm}$ no boundary conditions are employed. It was also considered that, under free expansion, each direction will expand in the same way as the isotropic problem, as shown in $[1,26]$.

The concrete has the following properties: Young's modulus of $20 \mathrm{GPa}$, asymptotic volumetric strain of 0.001737 , reactivity index of 250.989 days, porous filling time of 52 days, and calibration variables of 1.0, 1.0, 0.1 and 0.2 (porosity, humidity, stresses and temperature, respectively). Besides, we assume that the cube with sides of $30 \mathrm{~cm}$ is immersed in water with temperature of $38^{\circ} \mathrm{C}$.

Figure 3 shows the displacement sum considering the orthotropic expansion of AAR gel in several time steps, in order to observe the behavior of the cube under different boundary conditions. 


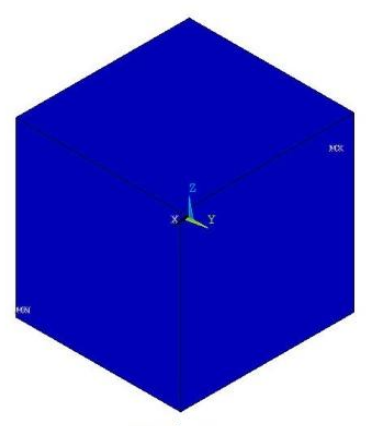

30 days

0.621e-4

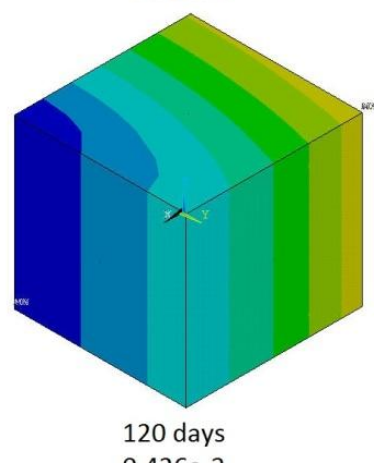

$0.426 \mathrm{e}-3$

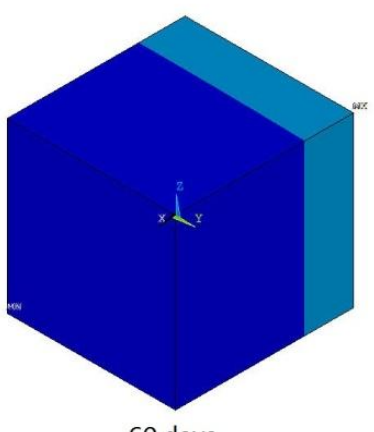

60 days

$0.872 \mathrm{e}-4$

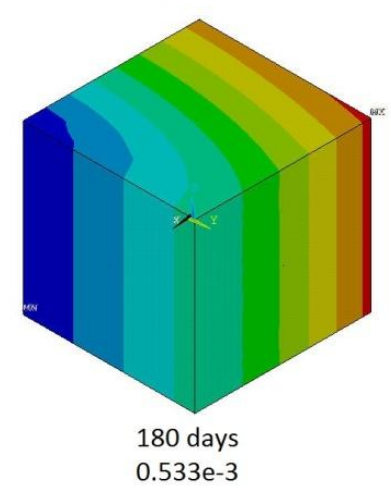

$0.533 \mathrm{e}-3$

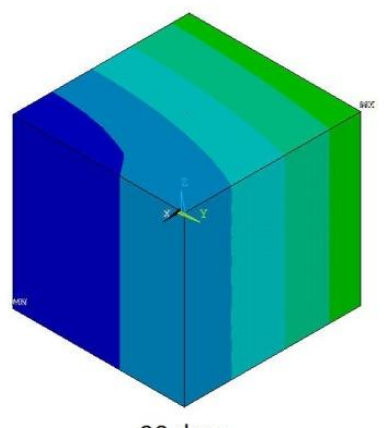

90 days

0.302e-3

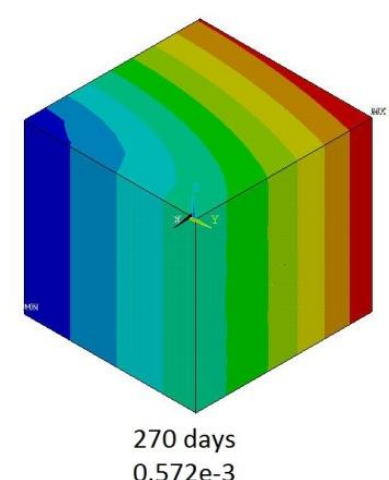

$0.572 \mathrm{e}-3$

$\begin{array}{cccccc}0.064 & 0.192 & 0.319 & 0.447 & 0.575 & \\ 0 . & 0.128 & 0.256 & 0.383 & 0.511\end{array}$

Figure 3. Cube expansion over time.

Figure 4 compares the results in each direction to the ones obtained by isotropic analysis, as well as with the experimental results for linear expansion obtained by [26]. One may notice that due to orthotropic behavior, the curves for expansion in $\mathrm{x}$ and $\mathrm{y}$ direction are not only displaced from each other, but completely different, resulting in expansion in $\mathrm{x}$ direction higher than the isotropic solutions and expansion in y direction lower than isotropic solution, as expected. The solution in the free direction (x) agrees very well with the experimental solution given by [26].

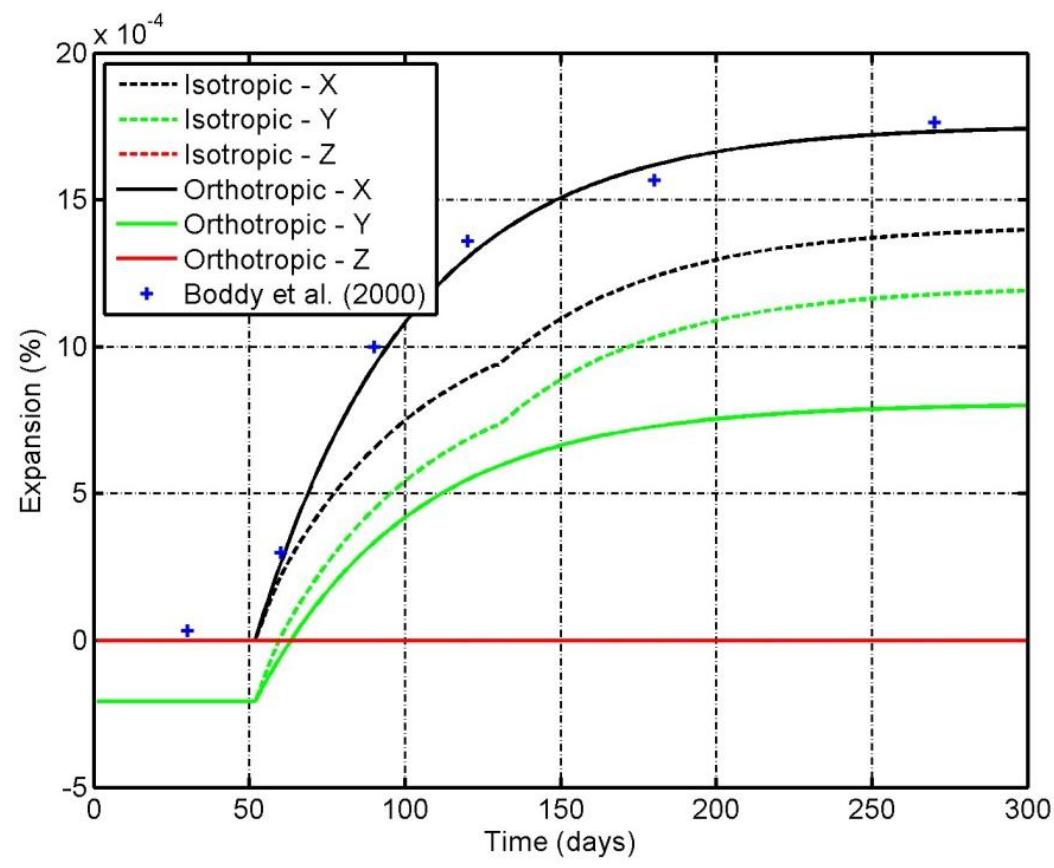

Figure 4. Orthotropic expansion. 


\subsection{Pine flat dam}

In this example a generic pine flat dam was modeled, considering reservoir loads and dam weight. Bar elements were positioned inside the dam, representing the dam monitoring system, and from those it was obtained the strain values due AAR, considering both isotropic and orthotropic gel expansion. The adopted properties were the same as in the previous example, as the objective is to apply the presented methodology to larger structures.

Figure 5 presents the problem geometry. Notice that at $\mathrm{z}=0$, displacements in $\mathrm{x}$ and $\mathrm{z}$ directions were constrained, and at $\mathrm{y}=0$ and $\mathrm{y}=300$, displacements in $\mathrm{x}$ and $\mathrm{y}$ directions were also constrained. Figure 6 shows the developed stresses in z-direction due to all loads in the last time step, and Figure 7 shows the displacement modulus of both studied cases.

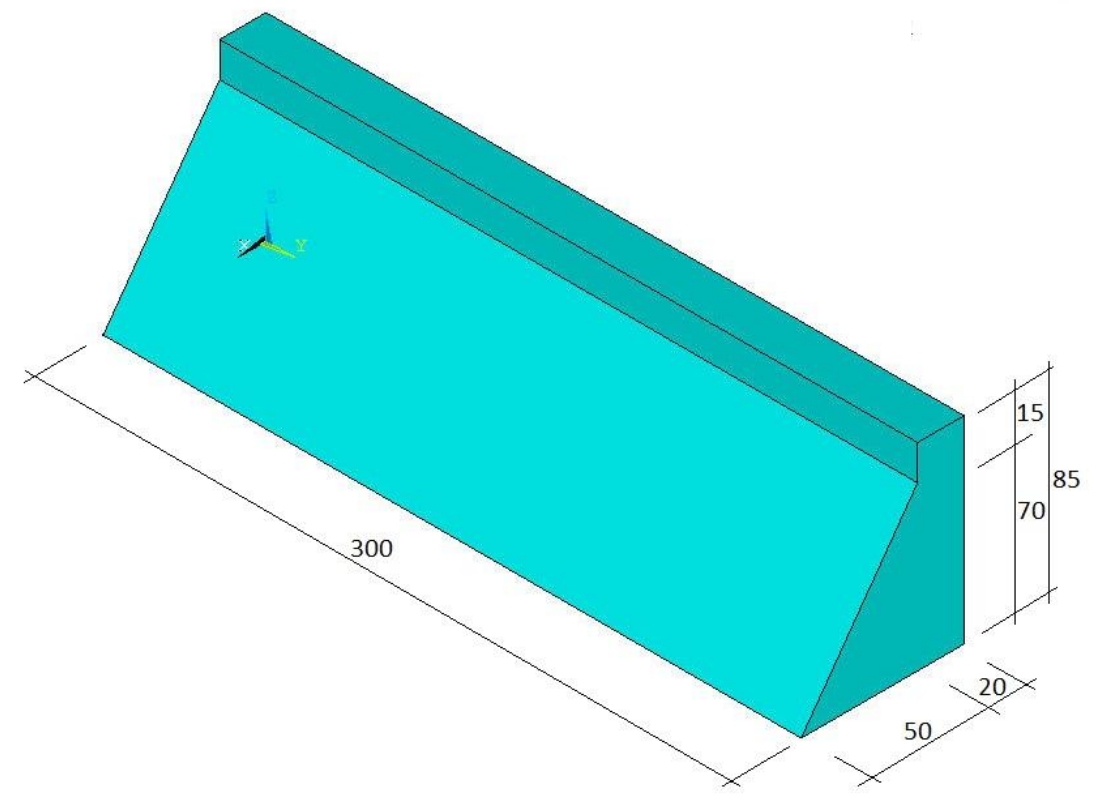

Figure 5. Generic Pine Flat Dam.

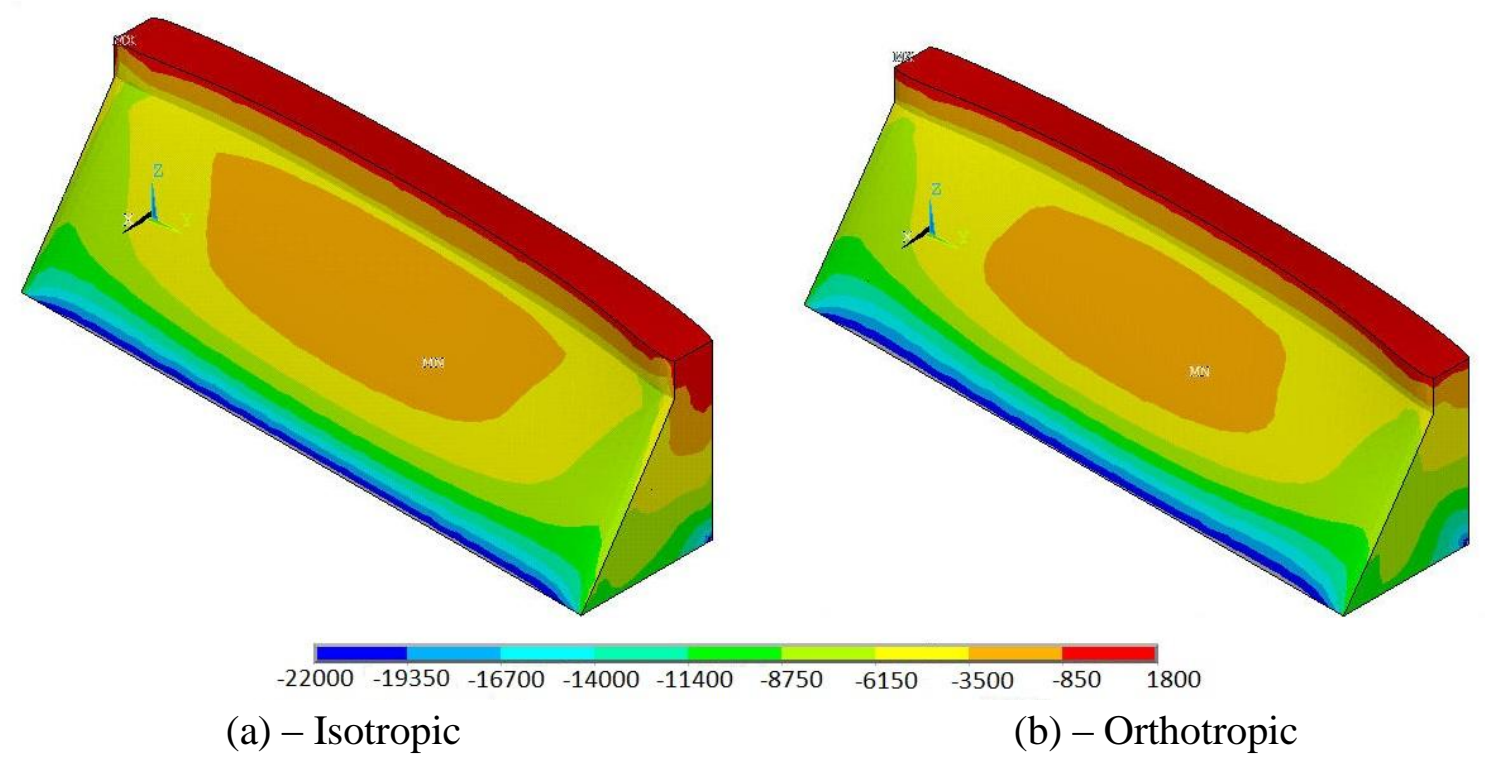

Figure 6. Z normal stress components. 


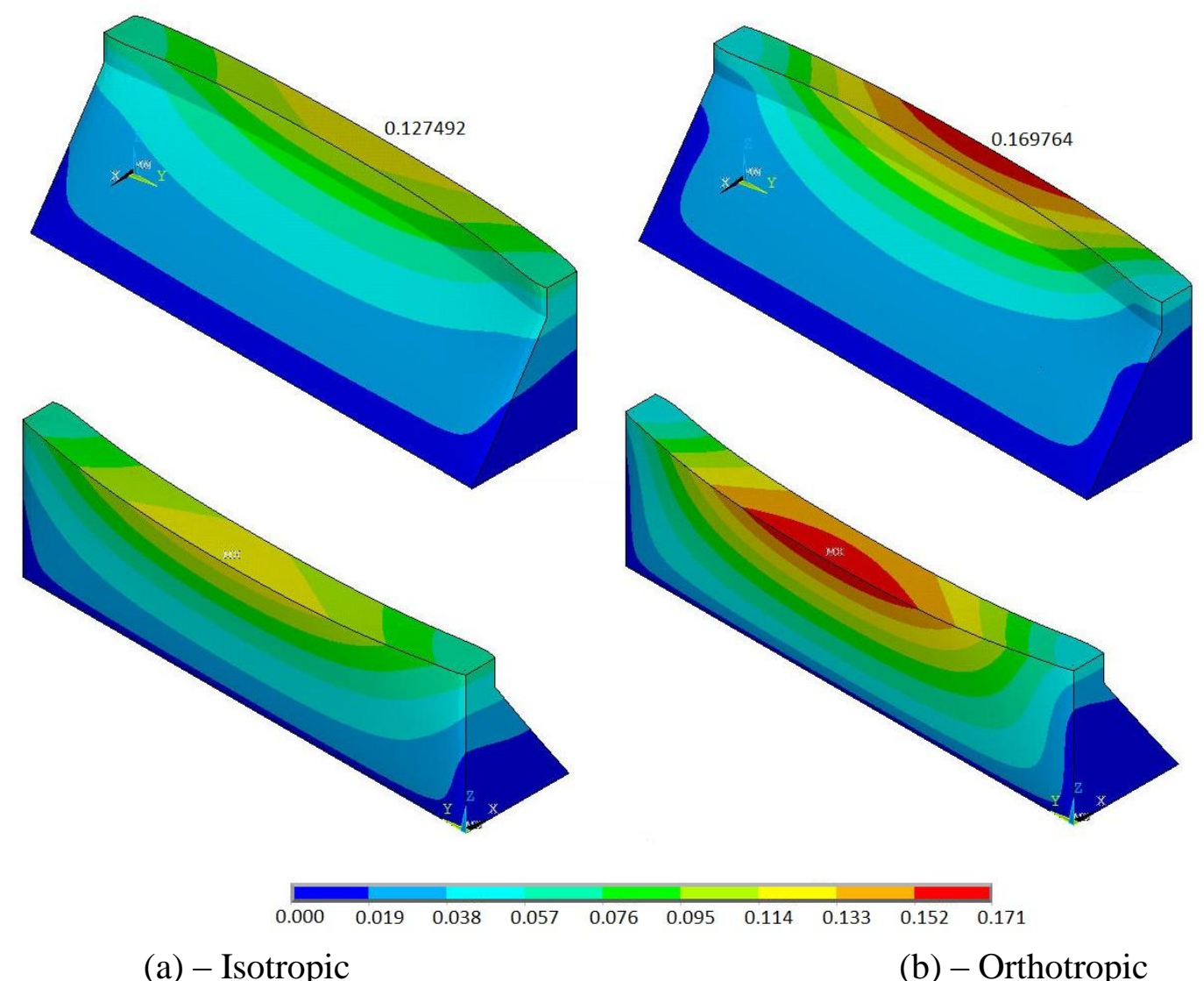

Figure 7. Displacement modulus.

Figure 8 shows the isotropic and orthotropic expansions measured by the virtual monitoring system. The first measuring bar was positioned in $\mathrm{z}$ direction, covering the 85 meters height, in which expansion was restrained due gravitational forces. The second measuring bar was positioned along $\mathrm{Y}$ direction, in which expansion was constrained due to foundations along faces $y=0$ and $y=300 \mathrm{~m}$. The third and forth measuring bars were positioned in $X$ direction, at $\mathrm{z}=17.5 \mathrm{~m}$ and $\mathrm{z}=38.25 \mathrm{~m}$. Notice that the lower bar is subjected to higher pressure, leading to smaller gel expansion, as expected.

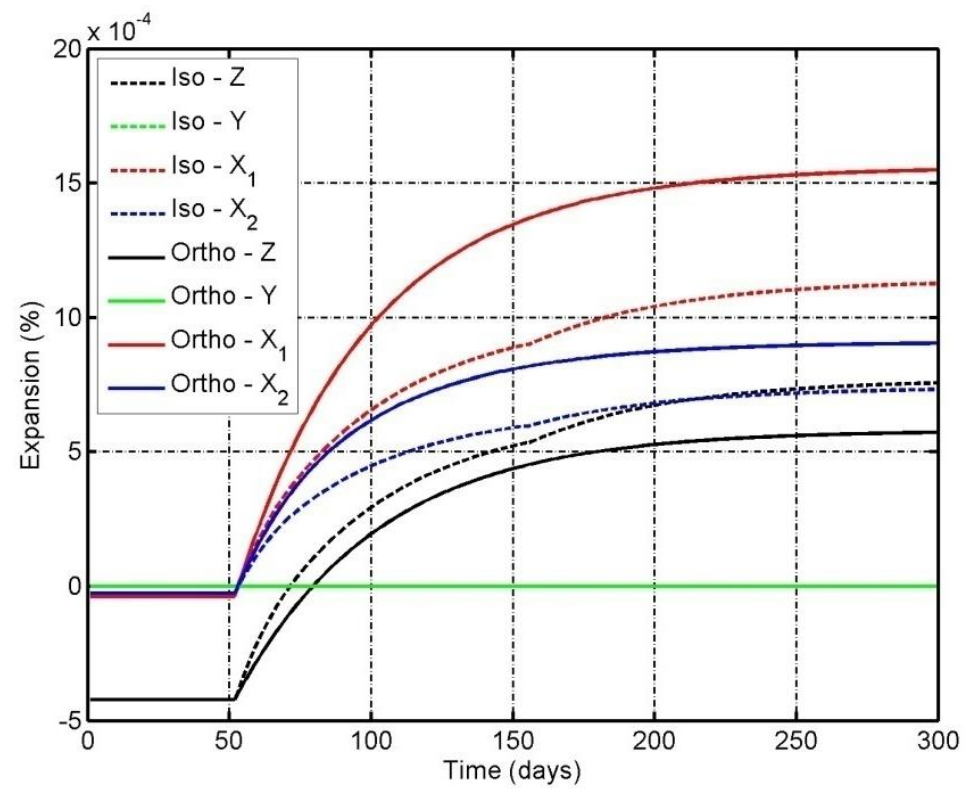

Figure 8. Expansion observed in the Virtual Monitoring system. 


\section{CONCLUSION}

A three dimensional orthotropic parametric model for the analysis of structures affected by the AAR expansion is proposed for implementation in the commercial finite element software ANSYS. Its performance was assessed by simulating AAR expansion in an accelerated mortar test and in a pine dam. Results were compared with a previous isotropic model. The orthotropic model established better correspondence with expected behavior.

Overall, the methodology performed well in both examples and is a promising tool to be applied to more complex structures, in which materials and conditions are not as simple as the ones employed for assessment. This subject should be considered in the next stage of this research. However, further validation tests should be carried out to assess the programmed routines.

\section{Acknowledgements}

The financial support provided by CEMIG and LACTEC through ANEEL R\&D program are gratefully acknowledged.

\section{REFERENCES}

[1] Carrazedo, R., Lacerda, L. A., "Parametric model for the analysis of concrete expansion due to alkali aggregate reaction." Journal of Strain Analysis for Engineering Design, 43, 325-335, 2008.

[2] Léger, P., Cöté, P., Tinawi, R., "Finite Element Analysis of Concrete Swelling due to alkali-aggregate reactions in dams." Computers \& Structures 60, 601-611, 1996

[3] Swenson, E. G., Gillott, J. E., "Alkali-carbonate rock reaction." Highway Research Board, 45, 1964.

[4] Svensson, S. E. "Eigenstresses generated by diffusion in a spherical particle embedded in an elastic medium." International Journal of Mechanical Sciences, 33, 211-233, 1991.

[5] Bazant, Z. P., and A. Steffens. "Mathematical model for kinetics of alkali-silica reaction in concrete." Cement and Concrete Research, 30, 419-428, 2000.

[6] Oberholster, R. E. "Alkali reactivity of silicious rock aggregates: diagnosis of the reaction testing of cement and aggregate and prescription of preventive measures." 6th International Conference of Alkalies in Concrete - Research and Practice. Copenhagen, 419-433, 1983.

[7] Capra, B., Bournazel, J. P., "Modeling of induced mechanical effects of alkali aggregate reactions." Cement and Concrete Research, 28, 251-260, 1998

[8] Farage, M. C. R. "Modelagem e Implementação Numérica da Expansão por Reação Álcali-Agregado do Concreto." Tese de Doutorado, Universidade Federal do Rio de Janeiro, Rio de Janeiro, 2000.

[9] Carey, G., Fowkes, N., Staelens, A., Pardhanani, A., "A class of coupled nonlinear reaction diffusion models exhibiting fingering." Journal of Computational and Applied Mathematics, 166, 87-99, 2004

[10] Chatterji, S., Christensen, P., "Studies of alkali-silica reaction. Part 7: Modelling of expansion." Cement and Concrete Research, 20, 285-290, 1990. 
[11] Pietruszczak, S. "On the mechanical behaviour of concrete subjected to alkali-aggregate reaction." Computers \& Structures, 58, 1093-1097, 1996.

[12] Pappalardo Jr, A. "Uma metodologia para a modelagem matemática de barragens de concreto afetadas pela reação álcali-agregado." Tese de Doutorado, Escola Politécnica da Universidade de São Paulo, São Paulo, 1988.

[13] Pappalardo Jr., A., Pauletti, R. M. O., Pimenta, P. M., "Simulação numérica da reação álcali-agregado em barragens de concreto." Revista Mackenzie de Engenharia $e$ Computação, 1, 181-199, 2000.

[14] Carrazedo, R., Lacerda, L. A., "A parametric discussion for the concrete expansion due to AAR." International Conferences on Alkali-Aggregate Reaction in Concrete. Beijing, 2004.

[15] Comby-Peyrot, I., Bernard, F., Bouchard, P.-O., Bay, F., Garcia-Diaz, E., "Development and validation of a 3D computational tool to describe concrete behaviour at mesoscale. Application to the alkali-silica reaction." Computational Materials Science, 46, 1163-1177, 2009.

[16] Dunant, C. F., Scrivener, K. L., "Micro-mechanical modelling of alkali-silica-reactioninduced degradation using the AMIE framework." Cement and Concrete Research, 40, 517-525, 2010.

[17] Comi, C., Fedele, R., Perego, U., "A chemo-thermo-damage model for the analysis of concrete dams affected by alkali-silica reaction." Mechanics of Materials, 41, 210-230, 2009.

[18] Farage, M. C. R., Alves, J. L. D., Fairbairn, E. M. R., "Macroscopic model of concrete subjected to alkali-aggregate reaction." Cement and Concrete Research, 34, 495-505, 2004.

[19] Fairbairn, E. M. R., Ribeiro, F. L. B., Lopes, L. E., Toledo-Filho, R. D., Silvoso, M. M., "Modelling the structural behaviour of a dam affected by alkali-silica reaction." Communications in Numerical Methods in Engineering, 22, 1-12, 2006.

[20] Bernardes, H. D. M., André, J. C., Castro, A. T. D., "Retro-análise na observação dos efeitos da reatividade álcali-agregado." Simpósio sobre reatividade álcali-agregado em estruturas de concreto. Goiânia, 1997.

[21] Bernardes, H. D. M., André, J. C., Rodrigues, R. D. O., "Observação de deformações em barragens de concreto sob reações álcali-agregado." Congresso Brasileiro de Concreto. Foz do Iguaçu: Instituto Brasileiro de Concreto, 2001.

[22] Cavalcanti, A. J. C. T., Silveira, J. F. A., Degaspare, J. C., "Análise dos efeitos da reação álcali-agregado (RAA) através de modelos matemáticos." XXIV Seminário Nacional de Grandes Barragens. Fortaleza: Comitê Brasileiro de Barragens, 2001.

[23] Lehtola, R., Vaz, L. E., Vargas Jr, E. A., Guedes, Q. M., "Modelos numéricos para a simulação da RAA em estruturas de concreto massa." Simpósio sobre Reatividade ÁlcaliAgregado em Estruturas de Concreto. Goiânia, 1997.

[24] Capra, B., Sellier, A., "Orthotropic modelling of alkali-aggregate reaction in concrete structures: numerical simulations." Mechanics of Materials, 35, 817-830, 2003.

[25] Carrazedo, R. "Modelagem numérica da expansão do concreto devido a reação álcaliagregado." Dissertação de Mestrado, Universidade Federal do Paraná, Curitiba, 2004.

[26] Boddy, A. M., Hooton, R. D., Thomas, M. D. A., "The effect of product form of silica fume on its ability to control alkali-silica reaction." Cement and Concrete Research, 30, 1139-1150, 2000. 